\title{
Reduced signaling through the hedgehog pathway in the uterine stroma causes deferred implantation and embryonic loss
}

\author{
Rebecca M Harman, Robert G Cowan, Yi Ren and Susan M Quirk \\ Department of Animal Science, College of Agriculture and Life Sciences, Cornell University, Ithaca, \\ New York 14853, USA \\ Correspondence should be addressed to S M Quirk; Email: smq1@ cornell.edu
}

\begin{abstract}
The role of the hedgehog $(\mathrm{HH})$ signaling pathway in implantation was studied in mice in which the $\mathrm{HH}$ signal transducer, smoothened (SMO), was conditionally deleted in the stromal compartment of the uterus, using CRE recombinase expressed through the Amhr2 ${ }^{\text {cre }}$ allele. In Amhr2 ${ }^{\text {cre/+ }} \mathrm{Smo}^{\text {null/flox }}$-mutant mice, Smo mRNA in uterine stroma was reduced $49 \%$ compared to that in $\mathrm{Amhr}^{+/+} \mathrm{Smo}^{\text {null/flox }}$ control mice, while levels in the luminal epithelium were not different. Litter size was reduced $60 \%$ in mutants compared with controls, but ovulation rate and the number of implantation sites on day 7 of pregnancy did not differ. The number of corpora lutea was equivalent to the number of implantation sites, indicating that most ovulations resulted in implanted embryos. However, on days 13 to 15 , the rate of embryo resorption was elevated in mutants. In control mice, on day 5 , implantation sites were present and blastocysts were well-attached. In contrast, blastocysts were readily flushed from uteri of mutant mice on day $\mathbf{5}$ and implantation sites were rare. On days 5.5 and 6, implantation sites were present in mutant mice, and by day 6 embryos could not be flushed from the uterus. The weight of implantation sites on day 7 was decreased by $42 \%$ in mutant mice, consistent with delayed development. Signaling through SMO in the endometrial stroma is required for optimal timing of implantation, and deferred implantation leads to defective embryo development and subsequent pregnancy loss.
\end{abstract}

Reproduction (2011) 141 665-674

\section{Introduction}

Preparation of the uterus for embryo implantation requires the actions of the ovarian steroids, progesterone and estrogen, as well as signaling through factors produced within the uterus, such as homeobox transcription factors, growth factors, cytokines and morphogens (Wang \& Dey 2006). The objective of the current study was to examine the role of one of these systems, the hedgehog $(\mathrm{HH})$ signaling pathway, in implantation in the mouse.

An understanding of factors that determine the time period during which the uterus is receptive to implantation was advanced by embryo transfer experiments in the mouse (Paria et al. 1993, Ma et al. 2003, Wang \& Dey 2006). These studies showed that during the first 3 days of pregnancy, the uterus is pre-receptive in that it provides an environment that is not harmful to blastocyst survival yet cannot support implantation. On day 4, a surge of estrogen production by the corpus luteum, known as the nidatory estrogen surge, triggers events in the uterus and embryo that are required for implantation. For example, estrogen acts on the uterus to increase expression of leukemia inhibitory factor (LIF) by the glandular epithelium, an event that is essential for implantation (Stewart et al. 1992, Chen et al. 2000). Simultaneously, luteal estrogen is converted to catecholestrogens within the uterus (Paria et al. 1998). These catecholestrogens, along with other uterine-derived molecules such as the endocannabinoids, act on receptors on the blastocyst to induce activation (Paria et al. 1998, Paria \& Dey 2000). The first evidence of attachment of the activated blastocyst to the uterus, which occurs on the evening of day 4 of pregnancy, is a localized increase in uterine vascular permeability. Actual penetration of the uterine epithelium and invasion of the embryo into the stroma occurs by about midnight on day 4 . On day 5 , the uterus becomes less receptive and no longer provides an optimal environment for the embryo or its implantation. There is a limited period of time during day 4, referred to as the window of receptivity, when the uterus can support implantation of an appropriately activated blastocyst.

There are physiological situations in which the blastocyst enters a state of dormancy and implantation is postponed. For example, mice may naturally experience delayed implantation if breeding occurs during lactation. In this case, blastocysts become dormant, while the uterus remains in a quiescent state until suckling ceases (Lopes et al. 2004). Delayed 
implantation can also be induced by removal of the ovaries from mice on the morning of day 4 of pregnancy, before the nidatory estrogen surge. If progesterone is administered, the blastocysts and uterus may be maintained in a suspended state for many days. Blastocyst activation and preparation of the uterus can then be initiated by treatment with estradiol (Paria et al. 1993). When delayed implantation occurs, the outcome of pregnancy is typically normal. In contrast, there are pathological situations in which alterations of factors in the embryo or uterus perturb the precise timing of implantation, often leading to pregnancy failure. The term 'deferred implantation' has been coined to distinguish this abnormal postponement from physiologically based delayed implantation (Wang \& Dey 2006). Deferred timing of implantation has been demonstrated in a number of genetically altered mouse models (Song et al. 2002, Ye et al. 2005, Wang et al. 2007a).

Signaling through the $\mathrm{HH}$ pathway has been identified as one of the factors important in regulating implantation (Lee et al. 2006, Franco et al. 2010). HH signaling is required for many developmental processes in the embryo and in adult tissues, and it is known to regulate cell proliferation, survival and differentiation (Hooper \& Scott 2005). There are three $\mathrm{HH}$ proteins, sonic $(\mathrm{SHH})$, desert $(\mathrm{DHH})$ and Indian $(\mathrm{IHH})$. These secreted $\mathrm{HH}$ ligands bind to a common membrane receptor, patched (PTCH1 or PTCH2). When PTCH1 is not bound by $\mathrm{HH}$ ligand, it maintains the transmembrane signal transducer smoothened $(\mathrm{SMO})$ in an inactive state. Binding of ligand to PTCH1 relieves inhibition of SMO and signaling occurs through GLI transcription factors (GLI1, GLI2 and GLI3). Expression of Gli1, Ptch1 and $\mathrm{HH}$-interacting protein (Hhip), are increased by $\mathrm{HH}$ signaling and thus serve as markers of HH signaling (Chen \& Struhl 1996, Marigo et al. 1996a, 1996b, Lee et al. 1997, Chuang \& McMahon 1999, Ikram et al. 2004).

Ihh is expressed in the luminal and glandular epithelium of the mouse uterus at very low levels on days 1 and 2 of pregnancy, and expression increases dramatically on day 3 in both luminal and glandular epithelium. On day 4, Ih $h$ expression decreases in the luminal epithelium but remains high in the glandular epithelium (Matsumoto et al. 2002). Patterns of $\mathrm{th} h$ expression in pregnant rats and hamsters are similar to that in the mouse (Khatua et al. 2006, Kubota et al. 2008). Treatment of ovariectomized mice with progesterone increased expression of thh in luminal and glandular epithelium (Matsumoto et al. 2002, Takamoto et al. 2002); the effect of progesterone was reduced in progesterone receptor (PGR) null mice (Takamoto et al. 2002), providing evidence that $I h h$ is a target of signaling through PGR. Treatment of ovariectomized mice, rats or hamsters with estradiol had no effect on expression of Ihh, and estradiol co-treatment with progesterone prevented the progesterone-induced increase in $\mathrm{thh}$
(Matsumoto et al. 2002, Khatua et al. 2006, Kubota et al. 2010). A more complicated picture emerged in studies with a rat delayed implantation model in which treatment with estradiol increased $I h h$ expression (Kubota et al. 2010). In addition to stimulation mediated through PGR, expression of Ihh was shown to be increased by injection of LIF (Wakitani et al. 2008). Studies to date indicate that expression of $/ h h$ increases in the luminal and glandular epithelium before implantation and that expression is regulated by steroid hormones and perhaps other mediators essential for implantation, such as LIF.

Mice with conditional deletion of $I h h$ in the uterus were previously created by using Cre recombinase, expressed under control of the Pgr locus, to elicit deletion of floxed alleles of $I h h$ (referred to as PR-CRE/Ihh $h^{f / f}$ mice in Lee et al. 2006). In PR-CRE/Ihh $h^{f / f}$ mice, embryos failed to attach to the luminal epithelium and implantation was blocked. Furthermore, in steroidprimed mutant mice, decidualization did not occur in response to a standard artificial decidualization stimulus. These results demonstrated that signaling through $\mathrm{IHH}$ is essential for implantation.

In the current study, the role of $\mathrm{HH}$ signaling in implantation was studied in mice in which Smo was conditionally reduced in the uterus by CRE expressed through the $A m h r 2^{\text {cre }}$ allele. Because $A m h r{ }^{\text {cre }}$ is expressed in the uterine stroma but not in the epithelium (Arango et al. 2005), the experiments provide insight into the importance of $\mathrm{HH}$ signaling to the stroma in implantation. A major phenotype observed is that the timing of implantation is deferred beyond the normal window of receptivity, resulting in embryonic loss later in pregnancy and reduced litter size. The data support a requirement for $\mathrm{HH}$ signaling to the stroma for normal timing of implantation. In addition, the results provide an example of an increasingly recognized phenomenon in which genetic alterations that defer the timing of implantation beyond the normal window of receptivity result in embryonic loss later in pregnancy.

\section{Results}

\section{Mice with conditional deletion of Smo in the uterus}

Mice with the Amhr2 ${ }^{\text {cre/+ }}$ allele were used to direct CREmediated deletion of Smo in the Mullerian duct and ovary. The Amhr $2^{\text {cre/+ }}$ allele was initially shown to direct CRE-mediated recombination in the gonads and in the mesenchyme of the developing Mullerian duct beginning at embryonic day 12.5 (Jamin et al. 2002). Mice of three different genotypes were used in the current study: 1) Amhr2 $2^{\text {cre/+}} S m o^{\text {null/flox }}$-mutant mice, which have one null Smo allele and one floxed Smo allele that can be inactivated by CRE-mediated recombination; 2) $A m h r 2^{+/+} S m o^{\text {null/flox }}$ genotype-matched control mice, which lack the Cre allele and thus maintain a 


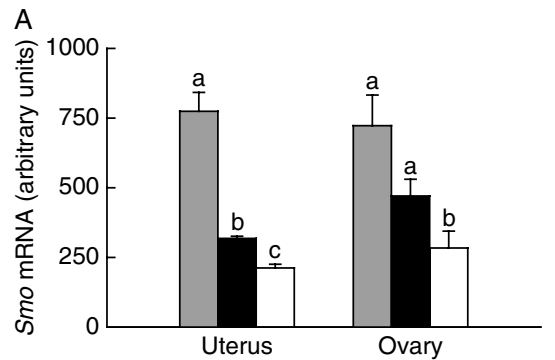

B

Luminal epithelia

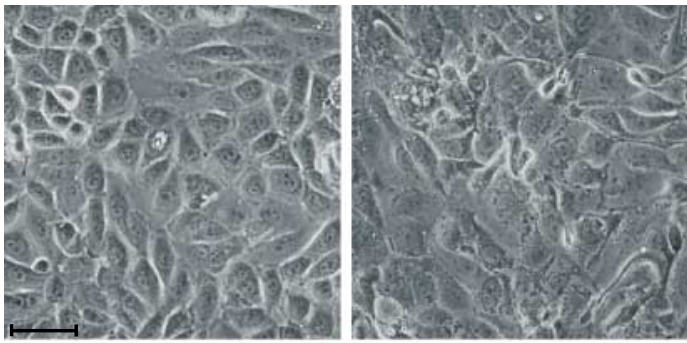

Live cells

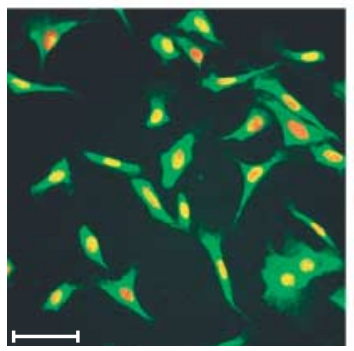

Cytokeratin (green) in fixed cells

C

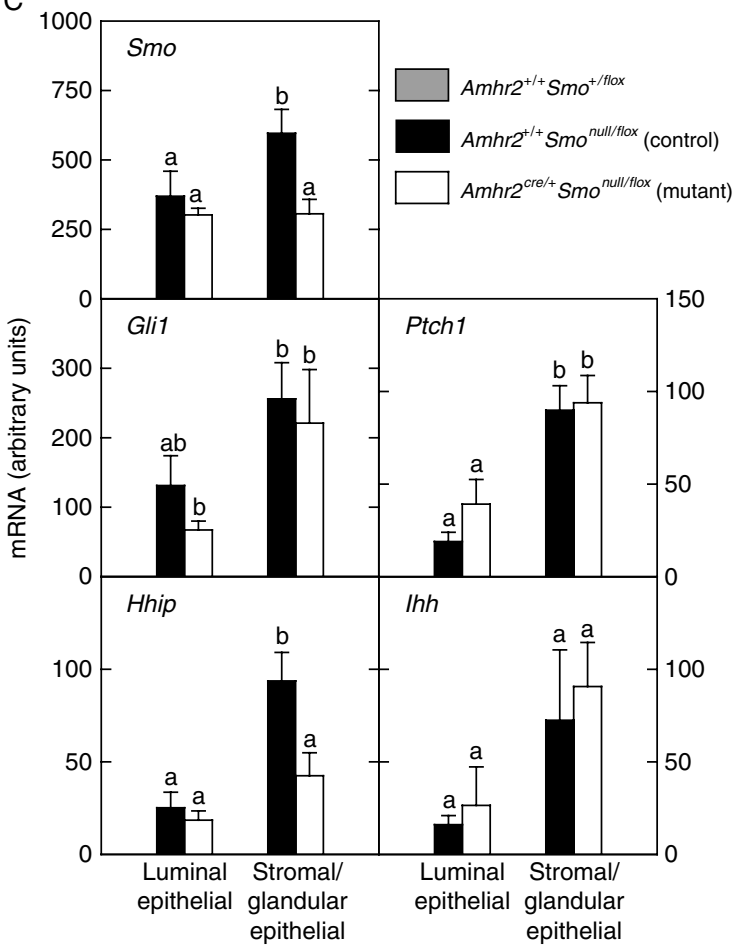

single functional floxed Smo allele; 3) Amhr2 ${ }^{+/+}$ $\mathrm{Smo}^{+/ \text {flox }}$ mice, which lack $\mathrm{Cre}$ and have two functional alleles of Smo.

The efficiency of CRE-mediated deletion of Smo was tested by measuring Smo mRNA levels in whole uteri on the morning of day 4 of pregnancy. As expected, $\mathrm{Amhr}^{+/+} \mathrm{Smo}^{+/ \text {flox }}$ mice, which have two functional alleles of Smo, had the highest levels of Smo mRNA (Fig. 1A). In Amhr2 ${ }^{+/+} S m o^{\text {null/flox }}$ mice, which have a single functional Smo allele, Smo mRNA levels were reduced by $58 \%$. CRE-mediated deletion of the floxed Smo allele in uteri of $A m h r 2^{\text {cre/+ }} \mathrm{Smo}^{\text {null/flox }}$ mice resulted in a further 33\% reduction of Smo mRNA levels. Smo mRNA levels in the ovary were also reduced by CRE-mediated recombination (Fig. 1A). In order to determine the localization of CRE-mediated recombination, enzymatic digestion of uteri isolated on the afternoon of day 4 of pregnancy was performed and a luminal epithelial cell fraction and a crude fraction of mixed endometrial cells containing stromal cells and glandular epithelial cells were obtained. Portions of each cell preparation were cultured to assess purity based on morphology and staining for the epithelial cell marker, cytokeratin. Cultures of luminal epithelial cells had the cobblestone appearance typical of epithelial cells and stained positively for cytokeratin (Fig. 1B). The stromal cell fraction had a small number of cytokeratin-positive cells that likely represent glandular epithelium and a large number of cytokeratin-negative cells with morphology typical of stromal cells (Fig. 1B). Smo mRNA levels were reduced $49 \%$ in the stromal cell fraction of $A m h r 2^{\text {Cre/+ }} S_{m o}$ null/flox -mutant mice compared with $A m h r 2^{+/+} S m o^{\text {null/flox }}$ control mice, whereas levels of Smo mRNA in luminal epithelial cells did not differ (Fig. 1C). These results are consistent with a previous report that the $A m h r 2^{\text {cre/+ }}$ allele drives CRE-mediated recombination in endometrial stromal cells and myometrium but not in luminal or glandular epithelium (Arango et al. 2005). Genes within the $\mathrm{HH}$ pathway that are known to be expressed at higher levels in response to $\mathrm{HH}$ signaling include Gli1, Ptch1 and Hhip (Chen \& Struhl 1996, Marigo et al. 1996a, 1996b,

Figure 1 (A) Expression of Smo mRNA in whole uterus and ovary from mice with two functional alleles of $\mathrm{Smo}\left(\mathrm{Amhr}^{+/+} \mathrm{Smo}^{+/ \text {flox }}\right)$, one functional allele of $\operatorname{Smo}\left(A m h r 2^{+/+} S m o^{\text {null/flox }}\right)$ or with conditional reduction of $\mathrm{Smo}$ expression $\left(A m h r 2^{\text {cre/+ }} \mathrm{Smo}^{\text {null/flox }}\right)$ on day 4 of pregnancy, as determined by quantitative real-time RT-PCR.

(B) Cytochemistry of uterine cell preparations. Phase contrast images of live, cultured luminal epithelial cells and stromal/glandular epithelial cells (top). Fixed cells were examined for cytokeratin expression (green), a marker of epithelial cells, by immunohistochemistry (bottom), with PI nuclear counter-staining (red). Scale bars $=50 \mu \mathrm{m}$. (C) Levels of mRNA for genes within the $\mathrm{HH}$ signaling pathway in enriched uterine luminal epithelial and stromal/glandular epithelial cell fractions prepared from $\mathrm{Amhr}^{+/+} \mathrm{Smo}^{\text {null/flox }}$ control and $\mathrm{Amhr} 2^{\text {cre/+}} \mathrm{Smo}^{\text {null/flox }}$-mutant mice on day 4 of pregnancy. In panels $A$ and $C$, bars represent the mean \pm S.E.M. of results obtained using three separate RNA preparations. Bars with different superscripts are significantly different $(P<0.05)$. 
Lee et al. 1997, Chuang \& McMahon 1999, Ikram et al. 2004). Each of these genes was detectable in both the luminal epithelial and stromal/glandular epithelial cell fractions (Fig. 1C). While levels of Gli1 and Ptch1 mRNA did not differ in the stromal cell fraction of mutant and control mice, levels of Hhip mRNA were reduced in mutants compared with controls. In the luminal epithelium, there were no differences in mRNA levels of Gli1, Ptch1 and Hhip between mutant and control mice. Levels of $I h h$ mRNA did not differ between mutant and control mice and were similar in the luminal epithelial and stromal/glandular epithelial cell fractions. Previous studies using in situ hybridization showed that Ih $\mathrm{h}$ is expressed at high levels in the luminal and glandular epithelium on day 3 of pregnancy, but by day 4 , levels of Ihh decrease in the luminal epithelium and remain elevated in the glandular epithelium (Matsumoto et al. 2002). The fact that levels of $I h h$ mRNA are similar in luminal epithelial and stromal cell fractions prepared from uteri on day 4 of pregnancy (Fig. 1C) is likely due to the presence of glandular epithelium in the stromal cell fraction.

\section{Assessment of fertility}

To assess fertility, mutant and control mice were caged with fertile CD-1 males for a period of 6 months and the number and size of litters were recorded. The average litter size was similar in $\mathrm{Amhr} 2^{+/+} \mathrm{Smo}^{+/ \text {flox }}$ mice (two functional Smo alleles; $8.6 \pm 0.5$ pups/litter) and $A m h r 2^{+/+} S_{m o}{ }^{\text {null/flox }}$ mice (one functional Smo allele; $9.3 \pm 0.4$ pups/litter) (Fig. 2). Litter size in Amhr2 ${ }^{\text {cre/t }}$ $S m o^{\text {null/flox }}$ mice with conditional reduction of $S m o$ in the uterus was reduced by $\sim 60 \%$ (3.9 \pm 0.4 pups/litter; $P<0.05)$. In $87 \%$ of mice with functional alleles of Smo, litters contained greater than five pups, with the majority of litters containing between 9 and 12 pups. In contrast, only $26 \%$ of litters from mice with conditional reduction of $\mathrm{Smo}$ in the uterus contained greater than five pups and ranged between 1 and 8 pups/litter (Fig. 2). Among mice of the three genotypes, there was no difference in the average interval between litters (ranging from 26 to 29 days) or in the percentage of pups that were weaned (ranging from 85 to $88 \%$ ).

In order to determine the cause of reduced litter size, mice were tested for differences in ovulation rate in response to superovulation. There was no significant difference in the number of ova recovered from the oviducts of $\mathrm{Amhr} 2^{\mathrm{Cre} /+} \mathrm{Smo}^{\text {null/flox }}$-mutant mice and Amhr2 ${ }^{+/+} \mathrm{Smo}^{\text {null/flox }}$ control mice tested at three different ages: $23-25,60-90$ and $170-200$ days of age (Fig. 3).

\section{Examination of implantation}

To further investigate the cause of reduced litter size in mutant mice, the number of implantation sites and

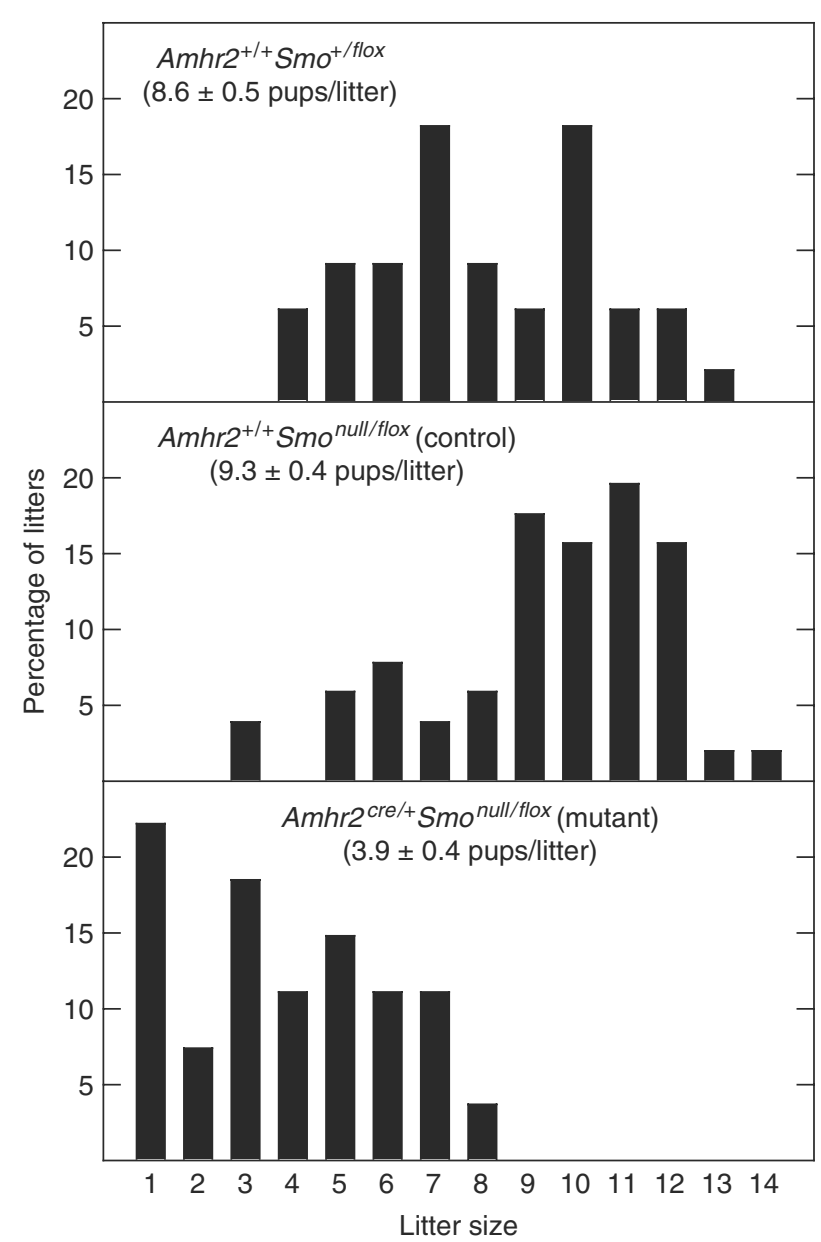

Figure 2 The distribution of litter sizes generated by continuous caging of transgenic female mice with fertile CD-1 males over a 6 -month period. Female mice with two functional alleles of $S m o\left(A m h r 2^{+/+}\right.$ $\mathrm{Smo}^{+/ \text {flox }}, 33$ litters from five mice, top panel), one functional allele of Smo $\left(A m h r 2^{+/+} S_{m o}{ }^{\text {null/flox }}, 51\right.$ litters from eight mice, middle panel) or with conditional reduction of $S m o$ expression $\left(A m h r 2^{\text {cre/+ }} S m o^{\text {null/flox }}\right.$, 27 litters from five mice, bottom panel) were tested. The average number of pups/litter \pm S.E.M. is shown in parentheses.

newly formed corpora lutea were counted on day 7 of pregnancy. Female mice were caged with fertile males beginning on day 28 of age and examined daily for the presence of a vaginal plug. On day 7 of pregnancy, implantation sites, which have increased vascular permeability, were identified by i.v. injection of Chicago blue and counted. Using mice that were mated at the time of their first estrous cycle facilitated the accurate counting of newly formed corpora lutea on the surface of the ovary. There were no differences in the number of corpora lutea or implantation sites in mutant mice compared with controls and there was no difference in the spacing between implantation sites (Fig. 4A). The fact that the number of corpora lutea and the number of implantation sites were both similar in mutant and control mice suggested that the majority of ovulated oocytes resulted in implanted embryos on day 7 of 


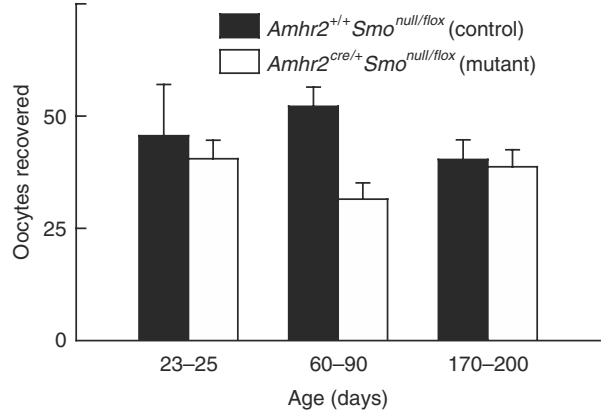

Figure 3 The number of oocytes recovered from ampullae after superovulation was determined in $\mathrm{Amhr}^{+/+} \mathrm{Smo}^{\text {null/flox }}$ control and $A m h r 2^{\text {cre/+}}{ }^{S m o} o^{\text {null/flox }}$-mutant mice at different ages. Bars represent the mean \pm s.E.M. of four to seven mice/group. There were no significant differences among groups.

pregnancy. These data, together with the reduced litter size in mutants relative to controls, suggested that embryonic loss might occur in mutant mice after day 7 of pregnancy. Examination of reproductive tracts on days 13 and 14 of pregnancy showed a significant reduction in the number of implantation sites in mutant mice compared with controls but no difference in the number of corpora lutea (Fig. 4A). The percentage of fetuses undergoing resorption was $40 \%$ in mutant mice and only $5 \%$ in control mice (Fig. 4B). In addition, $20 \%$ of fetuses in mutant mice appeared obviously smaller (Fig. 4B). Histology of an implantation site in a mutant mouse on day 13 , in which the embryo was obviously smaller than other embryos within the tract, showed that the site had all of the expected layers (labyrinth, spongiotrophoblast and maternal decidua). However, necrotic cells were present in the decidua, and the blood vessels in the labyrinth layer were more distended with blood than those in the placenta from control mice (Fig. 4C). A resorption site showed signs of fragmenting nuclei and breakdown of the walls of blood vessels in the placenta (Fig. 4C). The levels of progesterone in serum between days 4 and 13 of pregnancy did not differ in $\mathrm{Amhr}^{\text {cre/+ }} \mathrm{Smo}^{\text {null }}$ flox -mutant mice and $\mathrm{Amhr}^{+/+} \mathrm{Smo}^{\text {null/flox }}$ control mice, suggesting that embryonic loss was not due to insufficient luteal function (Fig. 5). Examination of the gross morphology of the reproductive tracts and hematoxylin and eosin-stained cross sections of the uterus and oviducts in $\mathrm{Amhr} 2^{\mathrm{Cre} /+} \mathrm{Smo}^{\text {null/flox }}$-mutant mice and $\mathrm{Amhr}^{+/+} \mathrm{Smo}^{\text {null/flox }}$ control mice revealed no detectable differences (data not shown).

\section{Determination of the timing of implantation}

The timing of implantation is known to be critical for successful development of embryos to term and normally occurs around midnight on day 4 of pregnancy. In order to determine the time of implantation, implantation sites were observed after injection of Chicago blue on day 5 or day 6 of pregnancy. Uteri were flushed to recover embryos that had failed to implant. On days 5 and 6 of pregnancy, only one or two embryos were recovered from 2 out of 13 control mice and Chicago blue-stained implantation sites were
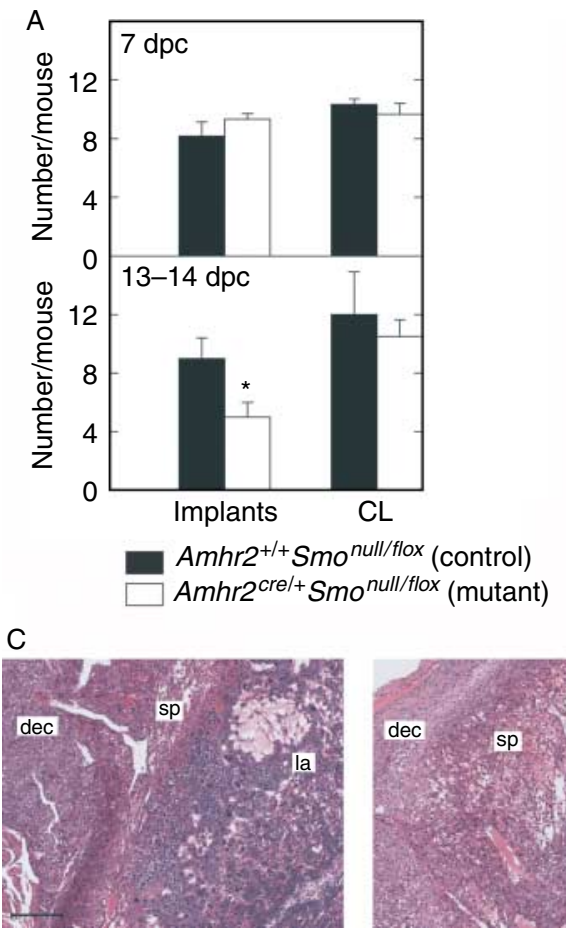

Control
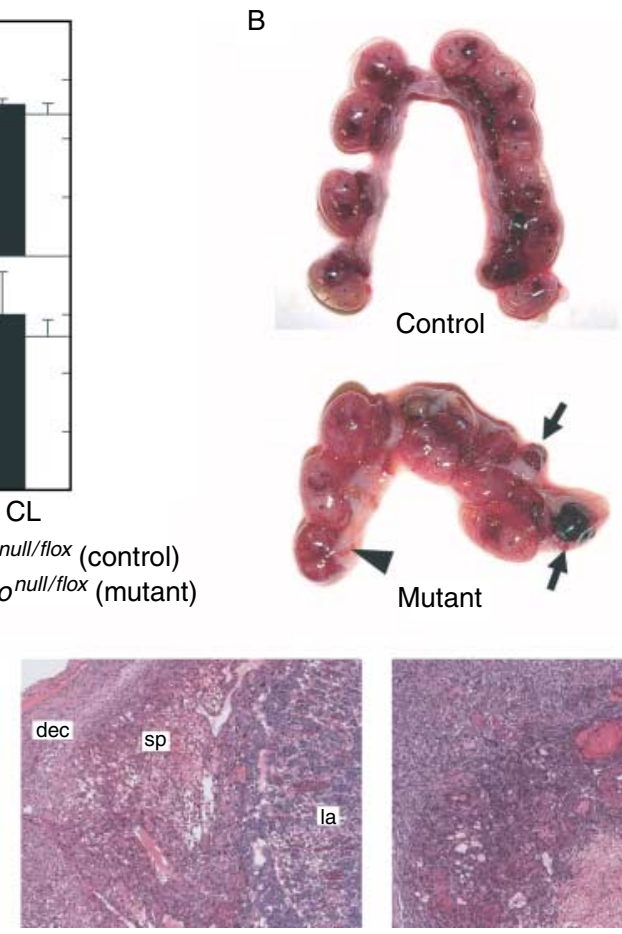

Mutant - small fetus

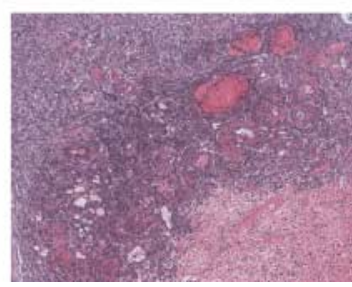

Mutant - resorption site
Figure $4(\mathrm{~A})$ The numbers of implantation sites and corpora lutea in $\mathrm{Amhr} 2^{+/+} \mathrm{Smo}^{\text {null/flox }}$ control and Amhr $2^{\text {cre/+ }} \mathrm{Smo}^{\text {null/flox }}$-mutant mice were examined on day 7 and on days 13-14 of pregnancy. Bars represent the mean \pm s.E.M. of six mice/group on day 7 and 4 mice/group on days 13-14. ${ }^{*} P<0.05$ versus the number of implantation sites in control mice at the same time point. Implantation sites with resorbing fetuses are not included in this data. (B) Implantation sites in control (upper image) and mutant (lower image) mice on days 13-14 of pregnancy. Arrows indicate resorption sites, and the arrowhead indicates an unusually small embryo. (C) Hematoxylin and eosin-stained sections through implantation sites on day 13 of pregnancy from a control and mutant mouse (site with a small embryo and a resorption site). la, labyrinth; sp, spongiotrophoblast; dec, decidua. Scale bar $=200 \mu \mathrm{m}$. 


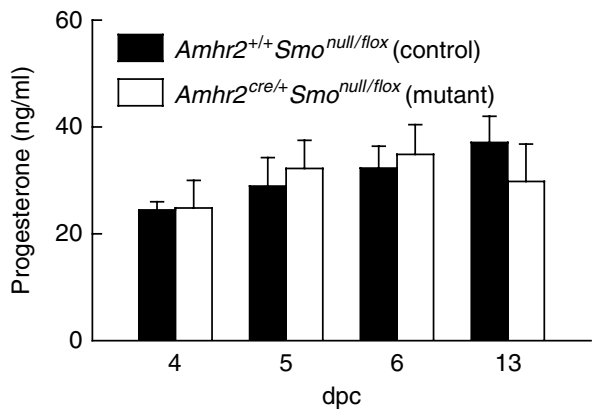

Figure 5 Serum progesterone concentration in $\mathrm{Amhr}^{+/+} \mathrm{Smo}^{\text {null/flox }}$ control and $A m h r 2^{\text {cre/+ }}$ Smo null/flox -mutant mice between 4 and 13 days of pregnancy. Bars represent the mean \pm s.E.M. of 4 mice/group. No significant differences were observed.

present, indicating that, as expected, implantation had occurred by the morning of day 5 (Fig. 6A and B). In contrast, embryos were readily flushed from mutant mice on day 5 and there were almost no implantation sites. By days 5.5 and 6, implantation sites were observed in mutant mice and while several embryos could be flushed from uteri on day 5.5, embryos could no longer be flushed on day 6 . Taken together, the data show that conditional reduction of Smo in the uterus leads to deferred implantation, beyond the normal window of receptivity. Implantation sites, including maternal and fetal components, were dissected from uteri on day 7 of pregnancy and weighed. Implantation sites were 1.6-fold heavier in control mice than in mutants $(7.8 \pm 0.8$ vs $4.5 \pm 0.8 \mathrm{mg} / \mathrm{site}, n=3 \mathrm{mice} /$ genotype analyzed, $P=0.0112$ ) (Fig. 6C), suggesting that deferred implantation was associated with developmental delay in embryos.

\section{Discussion}

CRE-mediated reduction in expression of Smo in the uterus caused deferred timing of implantation and embryonic loss later in pregnancy. Smo mRNA was reduced in the endometrial stroma, but not in the luminal epithelial cell fraction of uteri of mutant compared with control mice. This finding is consistent with previous reports that recombination through the $A m h r 2^{\text {cre/+ }}$ allele is restricted to the uterine stroma and fails to occur in the luminal or glandular epithelium (Arango et al. 2005). The results indicate that appropriate signaling through $\mathrm{SMO}$ in the endometrial stroma is required for implantation to occur with normal timing. In Amhr $2^{\text {cre/+ }}$ Smo ${ }^{\text {null/flox }}$-mutant mice, some embryos that implanted with delayed timing were successfully maintained to term while others were lost during midpregnancy. These findings point to the variable efficiency of the implantation reaction in mutant mice and the dramatic consequences on the success of pregnancy.

In a previous study, Ihh was conditionally deleted in the mouse uterus; Cre inserted into the Pgr locus effectively deleted floxed alleles of $I h h$ in the uterus. In these PR-CRE/Ihh ${ }^{f / f}$ mice, embryos failed to attach to the luminal epithelium and decidualization failed to occur in response to an artificial stimulus in steroid-primed mice (Lee et al. 2006). The authors of the study concluded that failed implantation was likely due to the loss of actions of epithelial-secreted $\mathrm{IHH}$ on the adjacent stroma. This conclusion is consistent with the localization of expression of components of the $\mathrm{HH}$ signaling pathway; Ih $h$ is clearly expressed in the luminal and glandular epithelium but not in the stroma, and Smo and Ptch1 are expressed prominently in the uterine stroma (Matsumoto et al. 2002, Takamoto et al. 2002). Recently, microarray analysis of uteri from PR-CRE/lhh ${ }^{f / f}$ mice was reported; ovariectomized PR-CRE/Ihh ${ }^{\text {ff/ }}$ mice
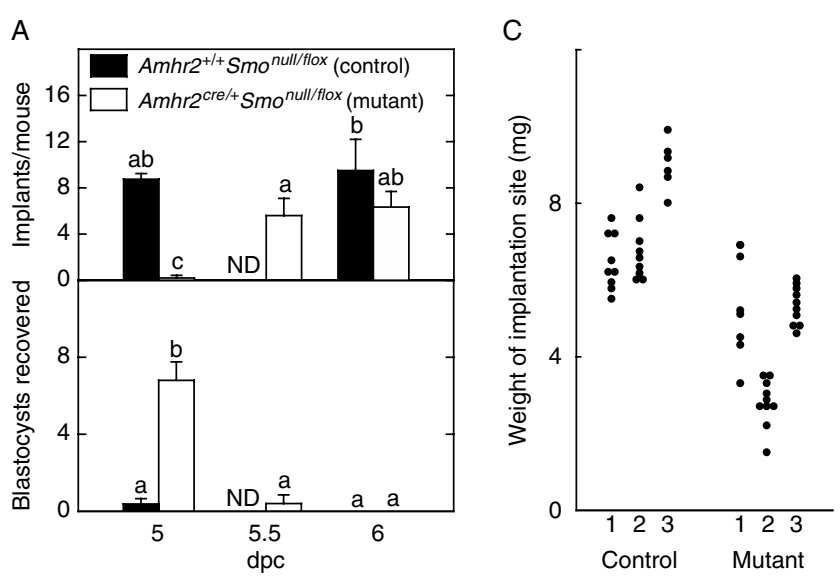

B
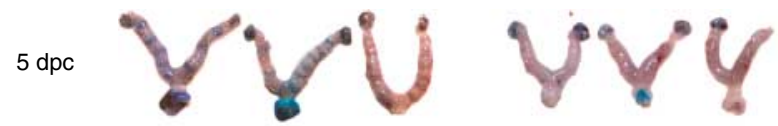

$5.5 \mathrm{dpc}$
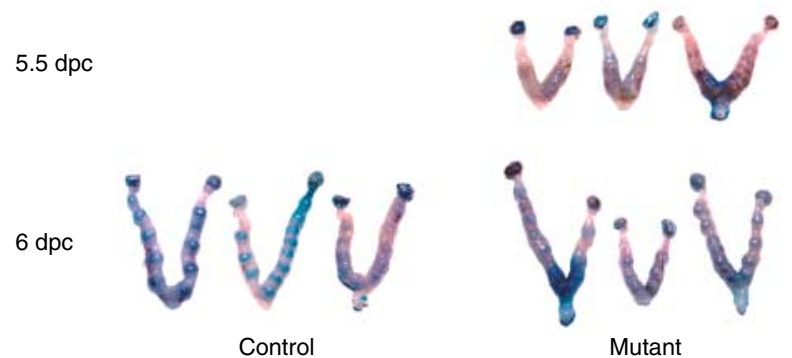

Figure 6 The number of visible implantation sites in uterine horns and the number of blastocysts recovered by flushing uteri (A) of $A m h r 2^{+/+}$ $\mathrm{Smo}^{\text {null/flox }}$ control and Amhr $2^{\text {cre/+ }} \mathrm{Smo}^{\text {null/flox }}$-mutant mice on days 5 , 5.5 and 6 of pregnancy. Bars represent the mean \pm s.E.M. of results obtained from four to eight mice/group. Bars with different superscripts are significantly different $(P<0.05)$. ND: no data was collected from control mice on day 5.5. (B) Whole uteri with attached ovaries collected on days 5, 5.5 and 6 of pregnancy. Implantation sites are easily visualized by Chicago blue staining in controls at both time points. In mutant mice, implantation sites are not visible on day 5 , faint sites become visible on day 5.5 and sites are prominent on day 6 . (C) The weights of individual implantation sites on day 7 of pregnancy in 3 control and 3 mutant mice are plotted. 
and control mice were treated with exogenous steroids to mimic day 3.5 of pregnancy (Franco et al. 2010). Genes that regulate the cell cycle, EGF signaling and estrogen signaling were identified and validated as being differentially expressed in PR-CRE/Ih $h^{f / f}$ mice.

It should be noted that there is evidence from a number of studies to suggest that effectors of $\mathrm{HH}$ signaling are expressed in the epithelium as well as in the stroma. In one study, in situ hybridization showed that Ptch1 is expressed in the luminal epithelium and periepithelial stroma at elevated levels on day 3 of pseudopregnancy compared with days 2 and 6 . In addition, mRNA levels of Hhip and Couptfll, genes for which transcription is increased by $\mathrm{HH}$ signaling, were also elevated in the epithelium and periepithelial stroma (Takamoto et al. 2002). In rats, the downstream target gene of $\mathrm{HH}$ signaling, Gli1, was expressed in the luminal epithelium as well as in the stroma on day 3.5 of pregnancy (Kubota et al. 2008). In the current study, quantitative RT-PCR showed expression of components of the $\mathrm{HH}$ signaling pathway typical of target cells in luminal epithelium of uteri on day 4 of pregnancy. Levels of Gli1, Ptch1 and Hhip mRNA in the luminal epithelial fraction of the uterus were within the same range as levels in the stromal/glandular epithelial fraction (Fig. 1). Therefore, it remains possible that there are autocrine effects of $\mathrm{HH}$ signaling within the epithelium as well as paracrine effects of $\mathrm{IHH}$ signaling on the stroma. While failure of implantation in PR-CRE/Ihh $h^{f / f}$ mice may be largely due to the removal of paracrine effects of $\mathrm{HH}$ signaling to the stroma, an additional autocrine effect of $\mathrm{IHH}$ signaling within the epithelium cannot be ruled out.

The different implantation phenotypes observed in Amhr2 ${ }^{\text {cre/+ }}$ Smo $^{\text {null/flox }}$ mice and PR-CRE/Ihh $h^{f / f}$ mice may have several explanations. First, reduction of Smo expression in the uterine stroma of $\mathrm{Amhr} 2^{\text {cre/+ }} \mathrm{Smo}^{\text {null/flox }}$ mice, as opposed to efficient gene deletion in PR-CRE/Ihh/f mice (Lee et al. 2006), may allow implantation to occur, albeit at a deferred time. The extended time interval to implantation might allow generation of sufficient activity of messengers that normally act downstream of SMO or may allow compensation by alternative pathways. The data suggest that Smo mRNA must be reduced below a critical threshold before implantation is impaired. In Amhr2 ${ }^{+/+} \mathrm{Smo}^{\text {null/flox }}$ mice harboring a single functional allele of $S m o$, whole uterine Smo mRNA was 50\% lower than in $\mathrm{Amhr}^{+/+} \mathrm{Smo}^{+/ \text {flox }}$ mice harboring two functional alleles of Smo, but fertility did not differ between these strains. In the stromal/glandular epithelial cell fraction of uteri in Amhr2 ${ }^{\text {cre/+ }}$ Smonull/flox mice, an additional $45 \%$ reduction in Smo mRNA, caused by CRE-mediated deletion of the floxed allele of Smo, was associated with defects in implantation. The fact that Smo mRNA was reduced rather than eliminated indicates that CRE-mediated recombination leads to the complete deletion of Smo in a fraction of stromal cells, and this was sufficient to impair implantation. Based on previous studies with the Amhr2 $2^{\mathrm{cr} /+}$ mouse, CRE-mediated recombination occurs in the stroma but not in the glandular epithelium (Arango et al. 2005); this feature would contribute to the fact that Smo mRNA was reduced rather than eliminated in the stromal/glandular epithelial cell fraction. For one out of the three transcriptional targets of $\mathrm{HH}$ signaling that were examined, levels of mRNA in the stromal/glandular epithelial cell fraction of uteri in mutant mice were reduced; Hhip mRNA was reduced in mutant mice, while Gli1 and Ptch1 did not differ between mutants and controls. It is likely that complex feedback mechanisms regulate the level of expression of these genes (Chen \& Struhl 1996); therefore, although they serve as useful markers of $\mathrm{HH}$ signaling activity under some conditions, they may provide imperfect measures in complex physiological situations involving multiple cell types in vivo.

An additional explanation for the different phenotypes observed in Amhrr ${ }^{\text {cre/+}} \mathrm{Smo} \mathrm{n}^{\text {null/flox }}$ mice and PR-CRE/Ihh ${ }^{f / f}$ mice is that reduction of $\mathrm{HH}$ signaling in the stroma alone (as in Amhr2 $2^{\text {cre/+ }} S m o^{\text {null/flox }}$ mice) may not be sufficient to block implantation, while reduction of $\mathrm{IHH}$ signaling in both epithelial and stromal compartments (as may occur in $\mathrm{PR}-\mathrm{CRE} / I h h^{f / f}$ mice) effectively prevents implantation. Further experiments would be necessary to test the role for $\mathrm{HH}$ signaling within the epithelium.

Deferred timing of implantation with subsequent embryonic loss, rather than blockage of implantation, was demonstrated in mice null for a number of genes, including cytosolic phospholipase $\mathrm{A}_{2 \alpha,}$ lysophosphatidic acid receptor $\mathrm{LPA}_{3}$, peroxisome proliferator-activated receptor $\delta$ and heparin-binding-EGF (Song et al. 2002, Ye et al. 2005, Wang et al. 2007a, Xie et al. 2007). For each of these null mouse strains, maternal deletion of the gene led to deferred timing of implantation and reduced litter size due to spontaneous pregnancy loss. These findings point to the potential importance of re-examining the phenotypes of previously studied genetically altered mice in which embryonic loss was noted, to determine whether the timing of implantation was affected. Deferred timing of implantation is also sufficient to induce developmental defects during late pregnancy in wild-type mice. Transfer of embryos to pseudopregnant wild-type mice on day 4 led to normal outcome of pregnancy while transfer on day 5 resulted in an increase in the rate of embryo resorption and retarded embryo development on day 12 (Song et al. 2002). Interestingly, when wild-type mice were tested by oil infusion into the uterus on day 4 or 5 of pseudopregnancy, the magnitude of the decidual response measured 4 days later did not differ (Song et al. 2002). These data suggest several different possibilities: first, the degree of decidualization is not affected by deferred timing of embryo implantation and does not contribute to later embryonic loss; second, the artificial decidual response to infusion of oil does not completely reflect possible differences in the capacity for decidualization in response to embryos transferred to 
recipients on day 4 compared with day 5 of pseudopregnancy. Although an artificial decidual response was not tested in the current study, it is possible that the degree of decidualization was reduced in $\mathrm{Amhr} 2^{\text {cre/ }+}$ $S m o^{\text {null/flox }}$ mice, since implantation sites on day 7 , which consist of decidual tissue and early embryos, were significantly smaller in mutant mice than in controls and showed a relatively high degree of variability among animals. The smaller size could be due to the decreased time available for development compared with that in control mice or to a direct effect of reduced $\mathrm{HH}$ signaling to impair decidualization. An effect of $\mathrm{HH}$ signaling on decidualization is supported by findings in PR-CRE/Ihh $h^{f / f}$ mice in which steroid priming of ovariectomized mice followed by a scratch to the uterine lumen failed to elicit a decidual response (Lee et al. 1997). It is believed that impaired implantation and decidualization can affect subsequent developmental steps, including placentation and embryonic growth (Wang \& Dey 2006, Wang et al. 2007a, 2007b).

Overall, the results of the current study demonstrate that $\mathrm{HH}$ signaling through $\mathrm{SMO}$ in the uterine stroma is required for normal timing of implantation and successful pregnancy. Further studies are warranted to test the potential requirement of $\mathrm{HH}$ signaling in the luminal epithelium for implantation. The results provide an additional example, in a growing list of studies, of how a relatively short deferral in the timing of implantation can generate an adverse 'ripple effect' that results in pregnancy failure (Wang \& Dey 2006).

\section{Materials and Methods \\ Materials}

Human chorionic gonadotrophin (hCG), equine chorionic gonadotrophin (eCG), hyaluronidase, DNase I and Chicago blue dye were purchased from Sigma-Aldrich. All tissue culture media and supplements were obtained from Invitrogen. Rabbit anti-pan-cytokeratin antibody (sc-15367) was purchased from Santa Cruz Biotechnology, Inc. (Santa Cruz, CA, USA). Purified rabbit IgG was obtained from Jackson ImmunoResearch Laboratories, Inc. (West Grove, PA, USA). Alexa Fluor 488conjugated goat anti-mouse $\lg \mathrm{G}$ and propidium iodide were obtained from Invitrogen. Genotyping and RT-PCR reagents were obtained from Applied Biosystems (Foster City, CA, USA). Tissue culture-treated 24-well plates and 35-mm dishes were obtained from Becton Dickinson (Franklin Lakes, NJ, USA). Titertek eight-well chamber slides were obtained from Nalge Nunc International (Rochester, NY, USA).

\section{Animals}

In the first step of a two-step breeding scheme, Amhr2 ${ }^{\text {cre/+ }}$ mice (Jamin et al. 2002), provided by Dr Richard Behringer, and Smo ${ }^{\text {null/+ }}$ mice (Zhang et al. 2001), purchased from The Jackson Laboratory (Bar Harbor, ME, USA), were mated to generate Amhr2 $2^{\text {cre/t+} S m o n u l l /+}$ mice. In the second step,
Amhr $2^{\text {cre/+ }}$ Smo $^{\text {null/t+}}$ male mice were bred to homozygous female $S m o^{\text {flox/flox }}$ mice (Long et al. 2001), purchased from The Jackson Laboratory, and progeny of the following genotypes were used in experiments: 1) Amhr2 ${ }^{\text {cre/+ }} S_{m o}{ }^{\text {null/flox }}$ mice, with the desired conditional deletion of Smo in the Mullerian duct; 2) $A m h r 2^{+/+} S m o^{\text {null/flox }}$ genotype-matched control mice lacking the Cre allele; 3) Amhr2 ${ }^{+/+} \mathrm{Smo}^{+/ \text {flox }}$ mice, lacking the Cre allele and having two functional alleles of Smo. PCR of tail DNA was used to determine the genotype (Long et al. 2001, Zhang et al. 2001, Jamin et al. 2002). Mice were maintained in accordance with the NIH Guide for the Care and Use of Laboratory Animals. Studies were approved by the Cornell University Institutional Animal Care and Use Committee.

\section{Assessment of fertility}

Fertility studies were performed by caging $A m h r 2^{\text {cre/+ }}$ Smo ${ }^{\text {null/flox }}$ females (mutants), Amhr2 ${ }^{+/+} S m o^{\text {null/flox }}$ females (controls) and $A m h r 2^{+/+} \mathrm{Smo}^{+/ \text {flox }}$ females (controls with two functional alleles of Smo) individually with fertile CD-1 males continuously for 6 months. The number of litters produced and the number of pups/litter were recorded. Superovulation experiments were carried out to determine if mutant mice ovulate normally. Mutant and control mice in three age groups; 23-25, 60-90 and 170-200 days were injected with 5 IU eCG i.p. After 48 h, they were given 5 IU hCG i.p. Mice were killed $20 \mathrm{~h}$ later. Reproductive tracts were removed, and ovaries with oviducts were cut away from uteri and placed in 35-mm culture dishes containing DMEM. Fine scissors were used to gently open the plump ampullae, releasing clustered oocytes into the media. Oocytes were transferred to $500 \mu \mathrm{l}$ DMEM in a 24-well tissue culture plate, treated with hyaluronidase to disperse the cumulus cells, and counted using an inverted phase contrast microscope.

Success of implantation was determined by counting recovered blastocysts and implantation sites at various time points during early pregnancy. Females were caged with fertile CD-1 males and examined daily for the presence of a copulatory plug, and the day of plug detection was designated day 1 of pregnancy or 1 day post coitum (dpc). Implantation was evaluated on 5, 5.5, 6, 7 or 13-14 dpc. Before euthanasia, $200 \mu \mathrm{l}$ of $2 \%$ (w:v) Chicago blue dye was injected into the maternal tail vein. After 5 min, animals were killed. Reproductive tracts were removed and corpora lutea on the surface of ovaries were counted using a dissecting microscope. Highly vascular implantation sites in the uterus are stained by Chicago blue and were easily identified, counted and recorded using a digital camera. On 5, 5.5 and $6 \mathrm{dpc}$, uteri of killed mice were flushed with DMEM and blastocysts that had not implanted were collected, transferred to $500 \mu \mathrm{l}$ DMEM in 24-well plates and counted. Uteri obtained $7 \mathrm{dpc}$ were fixed in Bouin's medium and implantation sites were subsequently removed and weighed.

\section{Measurement of progesterone in serum}

Serum obtained by cardiac puncture was stored at $-20^{\circ} \mathrm{C}$ until assayed for progesterone in duplicate using a Coat-a-Count Progesterone RIA kit purchased from Siemens Medical Solutions (Los Angeles, CA, USA). 


\section{Collection of uterine tissues}

Enriched populations of luminal epithelial and stromal cells were prepared from uteri obtained on the afternoon of day 4 of pregnancy and used for gene expression analysis. Reproductive tracts were removed and cleaned in DMEM-Ham's F12 Nutrient Mixture (DMEM-F12). Uterine horns were sliced open longitudinally, exposing luminal epithelial cells. Tissue was incubated in $3 \mathrm{ml}$ DMEM-F12 containing 0.075\% (w:v) trypsin, $0.3 \mathrm{mM}$ EDTA and $10 \mu \mathrm{g} / \mathrm{ml}$ DNase I in a $35 \mathrm{~mm}$ culture dish for $90 \mathrm{~min}$ at $37^{\circ} \mathrm{C}$. Luminal epithelial cells were removed from underlying tissue by gentle trituration with a large bore pipette every $30 \mathrm{~min}$. After $90 \mathrm{~min}$, medium containing luminal epithelial cells was transferred to a $15 \mathrm{ml}$ centrifuge tube and $0.5 \mathrm{ml}$ fetal bovine serum (FBS) was added to stop the enzymatic activity. Cells were pelleted by centrifugation, rinsed with DMEM-F12 and repelleted. Medium was removed, and the pellets were snap frozen in liquid nitrogen and held at $-80{ }^{\circ} \mathrm{C}$ for RNA extraction. Remaining uterine tissue was placed in $3 \mathrm{ml}$ fresh enzyme solution and digested at $37^{\circ} \mathrm{C}$ for $2 \mathrm{~h}$ with gentle trituration every $30 \mathrm{~min}$. At the end of $2 \mathrm{~h}$, undigested myometrium was discarded. Medium containing stromal cells was transferred to a $15 \mathrm{ml}$ centrifuge tube, enzyme activity was terminated as above, and the cells were rinsed, pelleted and frozen as above.

In order to visualize enriched luminal epithelial and stromal cell preparations, cells from non-pregnant mice were collected as above and cultured. After washing in DMEM-F12, cells were resuspended in DMEM-F12 with 5\% (v:v) FBS, $100 \mathrm{U} / \mathrm{ml}$ penicillin, $100 \mu \mathrm{g} / \mathrm{ml}$ streptomycin, $0.25 \mu \mathrm{g} / \mathrm{ml}$ fungizone, $1 \mathrm{mM}$ pyruvate, $2 \mathrm{mM}$ glutamine, $5 \mu \mathrm{g} / \mathrm{ml}$ transferrin, $5 \mu \mathrm{g} / \mathrm{ml}$ insulin, $20 \mathrm{nM}$ sodium selenite and $10 \mathrm{ng} / \mathrm{ml}$ epidermal growth factor. Cells were plated in gelatin-coated wells of 24-well culture plates and eight-well chamber slides. After $24 \mathrm{~h}$ in culture, cells were observed, monolayers were gently rinsed and fresh medium was added. After $48 \mathrm{~h}$ in culture, cells were photographed under phase contrast using a Spot II Digital Camera (Diagnostic Instruments, Sterling Heights, MI, USA) coupled to a Nikon Diaphot 300 microscope (Melville, NY, USA).

\section{Cytochemistry}

Enriched luminal epithelial and stromal cell cultures were rinsed with PBS and fixed for 2 min in cold acetone. After rinsing three times with PBS, cells were incubated with rabbit anti-cytokeratin antibody or rabbit IgG diluted to $2.0 \mu \mathrm{g} / \mathrm{ml}$ in permeabilization buffer (50 mM PBS with $1.0 \%$ (v:v) FCS, $0.1 \%$ (w:v) saponin and $0.1 \%$ (w:v) sodium azide) for $1 \mathrm{~h}$ at $37^{\circ} \mathrm{C}$. Slides were rinsed three times with PBS. A solution of Alexa Fluor 488-conjugated goat anti-rabbit IgG diluted to $1.0 \mu \mathrm{g} / \mathrm{ml}$ and propidium iodide diluted to $0.5 \mu \mathrm{g} / \mathrm{ml}$ in permeabilization buffer was added and cells were incubated for $1 \mathrm{~h}$ at $37^{\circ} \mathrm{C}$. Slides were rinsed three times with PBS and cover slips were applied. Images were obtained under fluorescent illumination.

\section{Gene expression analysis}

RNA was prepared from whole ovaries and uteri using a RNeasy Mini Kit (Qiagen) and from enriched luminal epithelial and stromal cell fractions using a RNeasy Micro RNA Kit (Qiagen). RT reactions were carried out using a High Capacity cDNA RT Kit (Applied Biosystems). Real time RT-PCR assays for genes within the $\mathrm{HH}$ pathway were performed on an ABI Prism 7000 (Applied Biosystems) using mouse-specific TaqMan Gene Expression Assays from Applied Biosystems (Smo, Mm01162710_ml; Gli1, Mm00494645_m1; Ptch1, Mm00436026_m1; Hhip, Mm00469580_m1; Ihh, Mm00439613_m1). A standard curve generated from cDNA transcribed from RNA of pooled uterine stromal cells was used in the assay. Results were standardized by dividing by $18 \mathrm{~s}$ rRNA concentration (Applied Biosystems assay 4319413E) and multiplying by 100 .

\section{Statistical analyses}

Litter size, number of oocytes ovulated following superovulation, number of corpora lutea, number of implantation sites and concentration of progesterone in serum were analyzed by one-way completely randomized ANOVA. Tissue mRNA concentrations were analyzed using two-way completely randomized ANOVA. When ANOVA indicated overall significance, means were compared using the StudentNewman-Keul procedure. Serum progesterone concentrations and mRNA concentrations were log-transformed prior to analysis. Blastocyst weights were analyzed by Student's $t$-test.

\section{Declaration of interest}

The authors declare that there is no conflict of interest that could be perceived as prejudicing the impartiality of the research reported.

\section{Funding}

This work was supported by a Research Initiation Award from the National Science Foundation ADVANCE Institutional Transformation Grant to Cornell University (grant number 0547373).

\section{Acknowledgements}

The authors thank Dr Richard Behringer for providing Amhr2 $2^{\text {cre/t }}$ mice, Dr S K Dey for helpful discussions and Dr Donald Schlafer for assessment of placental histology.

\section{References}

Arango NA, Szotek PP, Manganaro TF, Oliva E, Donahoe PK \& Teixeira J 2005 Conditional deletion of $\beta$-catenin in the mesenchyme of the developing mouse uterus results in a switch to adipogenesis in the myometrium. Developmental Biology 288 276-283. (doi:10.1016/ j.ydbio.2005.09.045)

Chen Y \& Struhl G 1996 Dual roles for Patched in sequestering and transducing hedgehog. Cell 87 553-563. (doi:10.1016/S00928674(00)81374-4)

Chen JR, Cheng JG, Shatzer T, Sewell L, Hernandez L \& Stewart CL 2000 Leukemia inhibitory factor can substitute for nidatory estrogen and is essential to inducing a receptive uterus for implantation but is not essential for subsequent embryogenesis. Endocrinology 141 4365-4372. (doi:10.1210/en.141.12.4365) 
Chuang P \& McMahon AP 1999 Vertebrate Hedgehog signalling modulated by induction of a Hedgehog-binding protein. Nature 397 617-621. (doi:10.1038/17611)

Franco HL, Lee KY, Broaddus RR, White LD, Lanske B, Lydon JP, Jeong JW \& DeMayo FJ 2010 Ablation of Indian hedgehog in the murine uterus results in decreased cell cycle progression, aberrant epidermal growth factor signaling, and increased estrogen signaling. Biology of Reproduction 82 783-790. (doi:10.1095/biolreprod.109.080259)

Hooper JE \& Scott MP 2005 Communicating with hedgehogs. Nature Reviews. Molecular Cell Biology 6 306-317. (doi:10.1038/nrm1622)

Ikram MS, Neill GW, Regl G, Eichberger T, Frischauf AM, Aberger F, Quinn A \& Philpott M 2004 Gli2 is expressed in normal human epidermis and BCC and induces Gli1 expression by binding to its promoter. Journal of Investigative Dermatology 122 1503-1509. (doi:10. 1111/j.0022-202X.2004.22612.x)

Jamin SP, Arango NA, Mishina Y, Hanks MC \& Behringer RR 2002 Requirement of Bmpr1a for Mullerian duct regression during male sexual development. Nature Genetics 32 408-410. (doi:10.1038/ng1003)

Khatua A, Wang X, Ding T, Zhang Q, Reese J, DeMayo FJ \& Paria BC 2006 Indian hedgehog, but not histidine decarboxylase or amphiregulin, is a progesterone-regulated uterine gene in hamsters. Endocrinology 147 4079-4092. (doi:10.1210/en.2006-0231)

Kubota K, Yamauchi N, Matsumoto K, Watanabe R, Oozono S, Aramaki S, Wood C, Soh T \& Hattori MA 2008 Expression of hedgehog family genes in the rat during early pregnancy. Journal of Reproduction and Development 54 340-345. (doi:10.1262/jrd.20054)

Kubota K, Yamauchi N, Yamagami K, Nishimura S, Gobaru T, Yamanaka KI, Wood C, Soh T, Takahashi M \& Hattori MA 2010 Steroidal regulation of Ihh and Gli1 expression in the rat uterus. Cell and Tissue Research 340 389-395. (doi:10.1007/s00441-010-0945-0)

Lee J, Platt KA, Censullo P \& Ruiz i Altaba A 1997 Gli1 is a target of Sonic hedgehog that induces ventral neural tube development. Development 124 2537-2552.

Lee K, Jeong J, Kwak I, Yu CT, Lanske B, Soegiarto DW, Toftgård R, Tsai MJ, Tsai S, Lydon JP et al. 2006 Indian hedgehog is a major mediator of progesterone signaling in the mouse uterus. Nature Genetics $\mathbf{3 8}$ 1204-1209. (doi:10.1038/ng1874)

Long F, Zhang XM, Karp S, Yang Y \& McMahon AP 2001 Genetic manipulation of hedgehog signaling in the endochondral skeleton reveals a direct role in the regulation of chondrocyte proliferation. Development 128 5099-5108.

Lopes FL, Desmarais JA \& Murphy BD 2004 Embryonic diapause and its regulation. Reproduction 128 669-678. (doi:10.1530/rep.1.00444)

Ma WG, Song H, Das SK, Paria BC \& Dey SK 2003 Estrogen is a critical determinant that specifies the duration of the window of uterine receptivity for implantation. PNAS 100 2963-2968. (doi:10.1073/pnas. 0530162100)

Marigo V, Johnson RL, Vortkamp A \& Tabin CJ 1996a Sonic hedgehog differentially regulates expression of Gli and Gli3 during limb development. Developmental Biology 180 273-283. (doi:10.1006/dbio.1996.0300)

Marigo V, Scott MP, Johnson RL, Goodrich LV \& Tabin CJ $1996 b$ Conservation in hedgehog signaling: induction of a chicken patched homolog by Sonic hedgehog in the developing limb. Development 122 1225-1233.

Matsumoto H, Zhao X, Das SK, Hogan BLM \& Dey SK 2002 Indian hedgehog as a progesterone-responsive factor mediating epithelialmesenchymal interactions in the mouse uterus. Developmental Biology 245 280-290. (doi:10.1006/dbio.2002.0645)
Paria BC \& Dey SK 2000 Ligand-receptor signaling with endocannabinoids in preimplantation embryo development and implantation. Chemistry and Physics of Lipids 108 211-220. (doi:10.1016/S0009-3084(00) 00197-3)

Paria BC, Huet-Hudson YM \& Dey SK 1993 Blastocyst's state of activity determines the "window" of implantation in the receptive mouse uterus. PNAS 90 10159-10162. (doi:10.1073/pnas.90.21.10159)

Paria BC, Lim H, Wang XN, Liehr J, Das SK \& Dey SK 1998 Coordination of differential effects of primary estrogen and catecholestrogen on two distinct targets mediates embryo implantation in the mouse. Endocrinology 139 5235-5246. (doi:10.1210/en.139.12.5235)

Song H, Lim H, Paria BC, Matsumoto H, Swift LL, Morrow J, Bonventre JV \& Dey SK 2002 Cytosolic phospholipase $A_{2 \alpha}$ is crucial for 'on-time' embryo implantation that directs subsequent development. Development 129 2879-2889.

Stewart CL, Kaspar P, Brunet LJ, Bhatt H, Gadi I, Kontgen F \& Abbondanzo SJ 1992 Blastocyst implantation depends on maternal expression of leukaemia inhibitory factor. Nature 359 76-79. (doi:10. 1038/359076a0)

Takamoto N, Zhao B, Tsai SY \& DeMayo FJ 2002 Identification of Indian hedgehog as a progestrone-responsive gene in the murine uterus. Molecular Endocrinology 16 2338-2348. (doi:10.1210/me. 2001-0154)

Wakitani S, Hondo E, Phichitraslip T, Stewart CL \& Kiso Y 2008 Upregulation of Indian hedgehog gene in the uterine epithelium by leukemia inhibitory factor during mouse implantation. Journal of Reproduction and Development 54 113-116. (doi:10.1262/jrd.19120)

Wang H \& Dey SK 2006 Roadmap to embryo implantation: clues from mouse models. Nature Reviews. Genetics 7 185-199. (doi:10.1038/ nrg1808)

Wang H, Xie H, Sun X, Tranguch S, Zhang H, Jia X, Wang D, Das SK, Desvergne B, Wahli W et al. 2007a Stage-specific integration of maternal and embryonic peroxisome proliferator-activated receptor $\delta$ signaling is critical to pregnancy success. Journal of Biological Chemistry 282 37770-37782. (doi:10.1074/jbc.M706577200)

Wang C, Ruther U \& Wang B 2007b The Shh-independent activator function of the full length Gli3 protein and its role in vertebrate limb digit patterning. Developmental Biology 305 460-469. (doi:10.1016/j.ydbio. 2007.02.029)

Xie H, Wang H, Tranguch S, Iwamoto R, Mekada E, Demayo FJ, Lydon JP, Das SK \& Dey SK 2007 Maternal heparin-binding-EGF deficiency limits pregnancy success in mice. PNAS 104 18315-18320. (doi:10.1073/ pnas.0707909104)

Ye X, Hama K, Contos JJ, Anliker B, Inoue A, Skinner MK, Suzuki H, Amano T, Kennedy G, Arai H et al. 2005 LPA $_{3}$-mediated lysophosphatidic acid signalling in embryo implantation and spacing. Nature 435 104-108. (doi:10.1038/nature03505)

Zhang XM, Ramalho-Santos M \& McMahon AP 2001 Smoothened mutants reveal redundant roles for Shh and Ihh signaling including regulation of L/R asymmetry by the mouse node. Cell 105 781-792. (doi:10.1016/ S0092-8674(01)00385-3)

Received 17 November 2010

First decision 20 December 2010

Accepted 9 February 2011 